\title{
PENERAPAN SIMULASI MONTE CARLO DALAM PENENTUAN HARGA OPSI ASIA
}

\author{
PUTRI RIZKA ATIKA YUSLI, RIRI LESTARI, YUDIANTRI ASDI \\ Program Studi Matematika, \\ Fakultas Matematika dan Ilmu Pengetahuan Alam, Universitas Andalas, \\ Kampus UNAND Limau Manis Padang, Indonesia, \\ email : putririzkaatikayusli@gmail.com
}

\begin{abstract}
Abstrak. Opsi Asia adalah opsi yang mempunyai nilai payoff bergantung pada ratarata harga saham selama masa opsi berlangsung. Penentuan harga opsi Asia dapat dilakukan dengan pendekatan terhadap rata-rata aritmatik. Karakterisik pendekatan terhadap rata-rata aritmatik adalah ketika harga saham berdistribusi lognormal, ini berarti rata-rata aritmatik harga saham tidak berdistribusi normal. Oleh karena itu, harga opsi Asia dapat ditentukan secara numerik diantaranya dengan simulasi Monte Carlo. Simulasi Monte Carlo memanfaatkan strong law of large dalam perhitungan. Semakin banyak jumlah simulasi yang dilakukan maka semakin baik pendekatan harga opsi Asia yang diperoleh. Berdasarkan hasil penelitian harga opsi Asia dengan berbagai simulasi diperoleh bahwa harga opsi Asia yang konvergen pada suatu nilai.
\end{abstract}

Kata Kunci: Opsi, Opsi Asia, Rata-rata Aritmatik, Monte Carlo

\section{Pendahuluan}

Dalam dunia keuangan, instrumen yang diperjualbelikan dalam pasar derivatif diantaranya berupa kontrak. Contoh kontrak yang paling populer diperdagangkan dalam pasar derivatif adalah opsi. Opsi adalah suatu kontrak atau perjanjian antara dua pihak dengan pihak pertama sebagai pembeli (holder) yang memiliki hak untuk membeli atau menjual suatu aset yang dimiliki pihak kedua sebagai penjual (writer) pada waktu pelaksanaan. Pihak pertama sebagai pemegang opsi tidak bisa dipaksakan untuk menjual atau membeli suatu barang yang disepakati. Hak untuk menjual atau membeli hanya bisa digunakan pada waktu pelaksanaan. Opsi tidak akan memiliki nilai apabila pada saat waktu pelaksanaan pemegang opsi tidak menggunakan haknya.

Opsi bisa digunakan untuk meminimalkan risiko dan memaksimalkan keuntungan dengan daya ungkit (leverage) yang lebih besar. Berinvestasi dalam bentuk opsi juga memberikan fungsi lindung nilai (hedging) terhadap saham induk. Dengan dana investasi yang relatif kecil, persentase keuntungan yang diperoleh relatif lebih besar dibandingkan dengan investasi pada saham. Namun demikian, risiko yang ditanggung akan lebih besar. Dengan adanya opsi, investor memiliki pilihan untuk menempatkan dananya dalam berbagai jenis instrument yang bertujuan mengurangi tingkat risiko.

Opsi eksotik adalah opsi yang nilai payoff opsi tidak hanya bergantung pada harga aset saat dilaksanakan, tapi juga bergantung pada harga-harga saham selama 
masa hidup opsi. Contoh opsi eksotik adalah Asian option (opsi Asia). Opsi Asia adalah opsi yang nilai payoff (nilai ekonomis yang diperoleh) opsi bergantung pada rata-rata harga saham selama masa opsi berlangsung.

Penentuan harga opsi saham (payoff) bertujuan untuk menentukan harga seimbang antara pembeli opsi dan penjual opsi sehingga tidak ada pihak yang terlalu diuntungkan dan dirugikan. Penentuan harga opsi Asia dapat dilakukan melalui pendekatan terhadap rata-rata Aritmatik. Karakteristik pendekatan terhadap ratarata Aritmatik adalah pada saat harga saham berdistribusi lognormal, rata-rata aritmatik harga saham sebarannya tidak diketahui.

Harga opsi Asia dengan rata-rata Aritmatik dapat ditentukan secara numerik diantaranya dengan simulasi Monte Carlo. Simulasi Monte Carlo adalah metode untuk menganalisa ketidakpastian, dimana tujuannya adalah untuk menentukan bagaimana bilangan acak mempengaruhi kestabilan dari sistem yang dimodelkan. Metode Monte Carlo merupakan metode yang memanfaatkan strong law of large number dalam melakukan perhitungan, artinya semakin banyak jumlah simulasi yang dilakukan semakin baik pula pendekatan nilai eksaknya. Simulasi Monte Carlo memanfaatkan penilaian risk-neutral (menginginkan keuntungan yang besar dengan resiko yang rendah) dimana nilai harapan payoff opsi yang didiskontokan pada suatu ukuran tertentu.

\section{Konsep Dasar}

Opsi berdasarkan jenis hak yang diberikan kepada pemegang opsi (holder) dibedakan menjadi dua yaitu opsi Call (opsi beli) dan opsi Put (opsi jual). Opsi Call memberikan hak kepada holder untuk membeli saham dengan harga pelaksanaan yang disepakati pada waktu jatuh tempo. Opsi Put memberikan hak kepada holder untuk menjual saham dengan harga pelaksanaan yang disepakati pada waktu jatuh tempo.

Tingkat pengembalian (return) yang diharapkan adalah keuntungan yang diterima dari investasi yang dilakukan pada waktu yang akan datang. Return dihitung dari rasio harga saham waktu ke $t+1$ dengan harga saham waktu ke $t$.

$$
R_{t}=\ln \frac{S_{t+1}}{S_{t}} ; t=1,2, \cdots, N-1
$$

Proses stokastik digunakan untuk memodelkan evolusi suatu sistem yang dijalankan pada suatu lingkungan yang tidak dapat diduga dimana model deterministik tidak lagi cocok dipakai untuk menganalisis maka digunakan proses stokastik.

\subsection{Model Harga Saham}

Pergerakan harga saham dikatakan memenuhi proses stokastik karena nilainya berubah terhadap waktu dengan pola yang tidak terduga. Misalkan harga saham $S(t)$ mengikuti proses Wiener yaitu adalah proses stokastik dimana harga saat ini berpengaruh untuk memprediksi harga yang akan datang. Pada interval waktu $d t$ perubahan harga saham dinyatakan dengan $d S(t)$. Maka perubahan harga saham dapat ditulis sebagai:

$$
d S(t)=\mu S(t) d t+\sigma S(t) d B(t)
$$


Asumsikan rata-rata tingkat pengembalian harga saham adalah bunga bebas resiko (risk-free rate), $\mu=r$. Selanjutnya fungsi saham yang dipengaruhi oleh waktu $Y(t)=g(S(t), t)$ dapat diperluas ke dalam deret Taylor orde kedua dapat dinyatakan dalam bentuk maka persamaan menjadi

$$
d Y(t)=\frac{\partial g}{\partial t} d t+\frac{\partial g}{\partial s} d S(t)+\frac{1}{2} \frac{\partial^{2} g}{\partial s^{2}}(d S(t))^{2}
$$

Salah satu asumsi Black-Scholes yaitu harga aset yang mendasari mengikuti proses Wiener yang mempunyai distribusi lognormal dengan parameter rataan dan variansi yang diketahui dan konstan. Logaritma harga saham pada saat jatuh tempo mempunyai sebaran normal dengan $\mu=\ln S(0)+\left(r-\frac{\sigma^{2}}{2}\right) T$ dan variansi $\sigma^{2}=\sigma^{2} T$. Sehingga solusi untuk persamaan harga saham saat waktu ke $t$

$$
S(t)=S(0) \exp \left(\left(r-\frac{\sigma^{2}}{2}\right) T+\sigma Z \sqrt{T}\right)
$$

\subsection{Simulasi Harga Saham}

Simulasi harga saham dilakukan dari masa awal pembelian saham hingga masa jatuh tempo, waktu yang diamati dibagi menjadi sebanyak $n$ buah waktu dengan panjang interval yang sama yaitu $\Delta t$ sehingga $n=\frac{T}{\Delta t}$ dengan $T$ adalah waktu jatuh tempo. Persamaan harga saham waktu ke $t_{i}$ dimana $i=1,2, \cdots, n$ dan $t_{n}=T$ menjadi

$$
S\left(t_{i}\right)=S\left(t_{i-1}\right) \exp \left(\left(r-\frac{\sigma^{2}}{2}\right) \Delta t+\sigma Z_{i} \sqrt{\Delta t}\right)
$$

\subsection{Pembentukan Model Harga Opsi Menggunakan Monte Carlo}

Opsi Asia adalah opsi yang mendasari rata-rata dari harga akhir setiap periode waktu. Rataan dari harga saham dapat dihitung dengan rataan aritmatik. Sehingga rata-rata dari harga saham menjadi

$$
\overline{S(T)}=\sum_{i=1}^{n} \frac{S\left(t_{i}\right)}{n}
$$

Payoff dari average price option menggunakan rata-rata aritmatik saat jatuh tempo untuk opsi Call Asia adalah $\max (S \overline{(T)}-K, 0)$. Harga opsi Call saat ini merupakan nilai harapan yang didiskon dan dinotasikan sebagai

$$
C=e^{-r T} \max (\overline{S(T)}-K, 0) .
$$

Payoff dari average price option menggunakan rata-rata aritmatik saat jatuh tempo untuk opsi Put Asia adalah $\max (K-\overline{S(T)}, 0)$. Harga opsi Put Asia dapat ditentukan dengan cara yang serupa seperti penentuan harga opsi Call Asia, yaitu $P=e^{-r T} \max (K-S \overline{(T)}, 0)$.

Apabila pengamatan sampel secara acak dilakukan sebanyak $M$ simulasi, $C_{i}$ menyatakan payoff dari opsi Call Asia dan $P_{i}$ menyatakan payoff opsi Put Asia yang diperoleh berdasarkan kemungkinan harga saham pada waktu $\mathrm{T}$. 
Payoff untuk harga opsi Call Asia ketika menggunakan metode Monte Carlo adalah $\hat{C}=\frac{1}{M} \sum_{i=1}^{M} e^{-r T} \max (S \overline{(T)}-K, 0)$. Standard error dari harga opsi Call adalah $S E=\sqrt{\frac{\hat{s}_{C}^{2}}{M}}$ dimana $\hat{s}_{C}^{2}=\frac{1}{M-1} \sum_{i=1}^{M}\left(P_{i}-\bar{P}^{2}\right)$.

Payoff untuk harga opsi Put Asia menggunakan metode Monte Carlo adalah $\left.\hat{P}=\frac{1}{M} \sum_{i=1}^{M} e^{-r T} \max (K-S \bar{T}), 0\right)$. Standard error dari harga opsi Put adalah $S E=\sqrt{\frac{\hat{s}_{P}^{2}}{M}}$ dimana $\hat{s}_{P}^{2}=\frac{1}{M-1} \sum_{i=1}^{M}\left(P_{i}-\hat{P}\right)^{2}$.

\section{Penerapan Penentuan Harga Opsi Asia dengan Menggunakan Simulasi Monte Carlo}

Sebelum menentukan harga opsi Asia, dilakukan perhitungan volatilitas return saham tahunan menggunakan data historis penutupan harga saham XL Group Ltd. periode 16 September 2015 sampai 16 September 2016 yang diakses dari http://www.yahoo.finance.com/. Faktor yang diperlukan dalam perhitungan volatilitas saham tahunan $s=\sqrt{N \hat{R}}=0.235834844$ dimana $\hat{R}=\frac{\sum_{i=1}^{N}\left(R_{i}-\hat{R}\right)^{2}}{N-1}=$ 0.000218969. Nilai untuk logaritma natural return $R_{t}=\ln \frac{S_{t+1}}{S_{t}}$ dan rataan dari logaritma natural return $\hat{R}=\frac{\sum_{t=1}^{N}}{N}=-0.00044382$.

Faktor yang juga diperlukan dalam menentukan harga opsi Asia harga saham awal pada tanggal 16 September $2016 S_{0}=33.52$, waktu jatuh tempo 14 Oktober 2016 maka panjang interval waktu menjadi $\Delta t=\frac{21}{365}=0.057534247$, tingkat suku bunga bebas resiko sebesar $r=7.5 \%$. Untuk harga pelaksanaan dan banyak simulasi dapat dilakukan penginputan pada program Matlab yang digunakan untuk menghitung harga opsi Asia.

Dalam penentuan harga opsi yang terbaik dari berbagai simulasi, akan dibandingkan nilai Standard Error dari harga opsi Call dan opsi Put dengan berbagai harga pelaksanaan untuk setiap banyaknya simulasi yang dilakukan. Nilai Standard Error dari harga opsi Call dan Put yang bernilai paing kecil adalah harga opsi simulasi 100000 kali.

Tabel 1. Harga Opsi Call Asia dan Opsi Put Asia serta Standard Error Simulasi Monte Carlo sebanyak 100.000 kali dengan Berbagai Harga Pelaksanaan

\begin{tabular}{|c|c|c|c|c|}
\hline $\begin{array}{c}\text { Harga } \\
\text { Pelaksanaan }\end{array}$ & $\begin{array}{c}\text { Harga } \\
\text { Opsi Call }\end{array}$ & $\begin{array}{c}\text { Standard Error } \\
\text { Opsi Call }\end{array}$ & $\begin{array}{c}\text { Harga } \\
\text { Opsi Put }\end{array}$ & $\begin{array}{c}\text { Standard Error } \\
\text { Opsi Put }\end{array}$ \\
\hline 25 & 10.133 & 0.0174 & 0.0183 & 0.000617 \\
30 & 5.5361 & 0.0159 & 0.3929 & 0.0036 \\
31 & 4.7582 & 0.0152 & 0.5861 & 0.0045 \\
32 & 4.0217 & 0.0144 & 0.8621 & 0.0056 \\
33 & 3.3732 & 0.0136 & 1.1969 & 0.0067 \\
34 & 2.7734 & 0.0126 & 1.666 & 0.0078 \\
35 & 2.2462 & 0.0114 & 2.1103 & 0.0090 \\
36 & 1.8495 & 0.0106 & 2.6348 & 0.0101 \\
37 & 1.4508 & 0.0094 & 3.2872 & 0.0111 \\
\hline
\end{tabular}

Harga opsi Call yang dihitung menggunakan simulasi Monte Carlo sebanyak 100000 kali lebih besar dari pada harga opsi Call di pasar saham. Kondisi ini se- 
baiknya bagi pemegang opsi untuk membeli opsi Call di pasar saham pada harga pelaksanaan tersebut. Harga opsi Put yang dihitung menggunakan simulasi Monte Carlo sebanyak 100000 kali lebih besar dari pada harga opsi Put di pasar saham. Kondisi ini sebaiknya bagi pemegang opsi untuk tidak menjual opsi $P u t$ di pasar saham pada harga pelaksanaan 25, 30,31,32, 33, 34, 35, 37. Untuk harga pelaksnaan 36 harga opsi Put yang dihitung menggunakan simulasi Monte Carlo sebanyak 100000 kali lebih kecil dari pada harga opsi $P$ ut di pasar saham. Kondisi ini sebaiknya bagi pemegang opsi untuk menjual opsi Put di pasar saham.

Perbandingan harga opsi Call dan Put dapat juga dilakukan dengan membandingkan dengan berbagai banyak simulasi.

Tabel 2. Harga Opsi Call Asia dan Opsi Put Asia Simulasi Monte Carlo dengan Berbagai Banyak Simulasi

\begin{tabular}{|c|c|c|c|}
\hline $\begin{array}{l}\text { Harga } \\
\text { Pelaksanaan }\end{array}$ & $2^{*}$ Jumlah Simulasi & $2 *$ Harga Opsi Call & 2*Harga Opsi Put \\
\hline $5 * 25$ & $\begin{array}{l}10 \\
100 \\
1000 \\
10000 \\
100000\end{array}$ & $\begin{array}{l}10.6185 \\
10.492 \\
10.1895 \\
10.1358 \\
10.1333\end{array}$ & $\begin{array}{l}0 \\
0.0029 \\
0.0111 \\
0.0130 \\
0.0183\end{array}$ \\
\hline $5 * 30$ & $\begin{array}{l}10 \\
100 \\
1000 \\
10000 \\
100000\end{array}$ & $\begin{array}{l}6.8433 \\
5.9953 \\
5.8535 \\
5.5613 \\
5.5361\end{array}$ & $\begin{array}{l}0.1358 \\
0.1996 \\
0.3477 \\
0.3920 \\
0.3929\end{array}$ \\
\hline $5^{*} 31$ & $\begin{array}{l}10 \\
100 \\
1000 \\
10000 \\
100000 \\
\end{array}$ & $\begin{array}{l}6.8034 \\
5.8695 \\
4.9735 \\
4.8044 \\
4.7582 \\
\end{array}$ & $\begin{array}{l}0.3061 \\
0.4572 \\
0.5710 \\
0.5763 \\
0.5961 \\
\end{array}$ \\
\hline 32 & $\begin{array}{l}10 \\
100 \\
1000 \\
10000 \\
100000 \\
\end{array}$ & $\begin{array}{l}5.5298 \\
4.2366 \\
4.1085 \\
4.0301 \\
4.0217 \\
\end{array}$ & $\begin{array}{l}0.4183 \\
0.7997 \\
0.8202 \\
0.8609 \\
0.8621 \\
\end{array}$ \\
\hline 33 & $\begin{array}{l}10 \\
100 \\
1000 \\
10000 \\
100000\end{array}$ & $\begin{array}{l}4.2052 \\
3.7455 \\
3.6390 \\
3.3823 \\
3.3732\end{array}$ & $\begin{array}{l}0.6851 \\
0.8557 \\
1.1084 \\
1.1810 \\
1.1969\end{array}$ \\
\hline 34 & $\begin{array}{l}10 \\
100 \\
1000 \\
10000 \\
100000\end{array}$ & $\begin{array}{l}3.4620 \\
3.1824 \\
2.9246 \\
2.8128 \\
2.7734\end{array}$ & $\begin{array}{l}0.7829 \\
1.4555 \\
1.5519 \\
1.6032 \\
1.6066\end{array}$ \\
\hline
\end{tabular}




\begin{tabular}{|l|l|l|l|}
\hline \multirow{3}{*}{35} & 10 & 3.2308 & 1.2501 \\
& 100 & 3.1592 & 1.7584 \\
& 1000 & 2.5265 & 1.9760 \\
& 10000 & 2.2513 & 2.0246 \\
& 100000 & 2.2462 & 2.1103 \\
\hline 36 & 10 & 2.1381 & 1.6912 \\
& 100 & 2.0393 & 2.2739 \\
& 1000 & 1.8923 & 2.6185 \\
& 10000 & 1.8514 & 2.6218 \\
37 & 100000 & 1.8495 & 2.6348 \\
\hline \multirow{3}{*}{} & 10 & 0.6572 & 2.8722 \\
& 100 & 1.5856 & 2.9064 \\
& 1000 & 1.5641 & 3.2112 \\
& 10000 & 1.4628 & 3.2409 \\
& 100000 & 1.4508 & 3.2872 \\
\hline
\end{tabular}

Berdasarkan tabel diatas diperoleh bahwa pada harga pelaksanaan 25 diperoleh harga opsi Call konvergen pada nilai 10.13 dan harga opsi Put konvergen pada nilai 0.01. Harga opsi dengan pelaksanaan 30 diperoleh harga opsi Call konvergen pada nilai 5.53 dan harga opsi Put konvergen pada nilai 0.39. Harga opsi dengan pelaksanaan 31 diperoleh harga opsi Call konvergen pada nilai 4.7 dan harga opsi Put konvergen pada nilai 0.5. Harga opsi dengan pelaksanaan 32 diperoleh harga opsi Call konvergen pada nilai 4 dan harga opsi Put konvergen pada nilai 0.86 . Harga opsi dengan pelaksanaan 33 diperoleh harga opsi Call konvergen pada nilai 3.3 dan harga opsi Put konvergen pada nilai 1.1. Harga opsi dengan pelaksanaan 34 diperoleh harga opsi Call konvergen pada nilai 2.7 dan harga opsi Put konvergen pada nilai 1.6. Harga opsi dengan pelaksanaan 35 diperoleh harga opsi Call konvergen pada nilai 2.25 dan harga opsi Put konvergen pada nilai 2. Harga opsi dengan pelaksanaan 36 diperoleh harga opsi Call konvergen pada nilai 1.8 dan harga opsi Put konvergen pada nilai 2.6. Harga opsi dengan pelaksanaan 37 diperoleh harga opsi Call konvergen pada nilai 1.4 dan harga opsi Put konvergen pada nilai 3.2.

\section{Penutup}

Penentuan harga opsi Asia menggunakan rata-rata aritmatik dilakukan melalui Simulasi Monte Carlo dapat dinyatakan sebagai berikut.

$$
\begin{aligned}
& \left.\hat{C}=e^{-r T} \frac{1}{M} \sum_{i=1}^{M} \max (S \bar{T})-K, 0\right) \\
& \hat{P}=e^{-r T} \frac{1}{M} \sum_{i=1}^{M} \max (K-S \overline{(T)}, 0)
\end{aligned}
$$


dimana

$$
\begin{aligned}
\hat{C} & : \text { harga opsi Call Asia } \\
\hat{P} & : \text { harga opsi Put Asia } \\
M & : \text { banyak simulasi } \\
r & : \text { risk-free rate } \\
T & : \text { waktu jatuh tempo } \\
K & : \text { harga pelaksanaan atau Strike Price } \\
S \overline{(T)} & : \text { rata-rata harga saham sepanjang hidup opsi }
\end{aligned}
$$

Penentuan harga opsi Asia dengan berbagai pelaksanaan akan diperoleh harga opsi Call akan semakin menurun jika harga pelaksanaan yang semakin meningkat. Untuk harga opsi Put diperoleh harga semakin meningkat jika semakin meningkatnya harga pelaksanaan. Untuk harga opsi Asia dengan berbagai simulasi diperoleh bahwa harga opsi Asia akan konvergen pada suatu nilai baik untuk opsi Call maupun opsi Put.

Simulasi Monte Carlo untuk harga opsi Asia diterapkan pada saham XL Group Ltd. Perhitungan ini dapat digunakan oleh pemegang opsi untuk memperkirakan harga opsi Asia yang digunakan dalam pelaksanaan opsi agar meminimalisir kerugian yang terjadi dalam mengelola aset.

\section{Ucapan Terima Kasih}

Penulis mengucapkan terima kasih kepada ibu Dr. Maiyastri, Bapak Dr. Jenizon, Ibu Nova Noliza Bakar, M.Si yang telah memberikan masukan dan saran sehingga paper ini dapat diselesaikan dengan baik.

\section{Daftar Pustaka}

[1] Adams, A. 2003. Investment Mathematics. John Wiley and Sons, Ltd., Canada.

[2] Bain, L. J dan Max E. 1991. Introduction To Probability and Mathematical Statistic. Duxbury, Canada.

[3] Closing price. 2016. Available from: http://finance.yahoo.com. [diakses pada 16 September 2016].

[4] Halim, A. 2005. Analisis Investasi. Salemba Empat, Jakarta.

[5] Hull, John C. 2003. Option, Future, and Other Derivatives. 5th Edition. Pearson Education Inc., New Jersey.

[6] Kwok, Yue-Kuen. 2008. Mathematical Models of Financial Derivatives. Second Edition. Springer Berlin Heidelberg.

[7] Ross, S.M. 1983. Stocastic Processes. John Wiley \& Sons Inc., Canada 